\title{
Caspase 3 involves in neuroplasticity, microglial activation and neurogenesis in the mice hippocampus after intracerebral injection of kainic acid
}

Tsai-Teng Tzeng ${ }^{1+}$, Huey-Jen Tsay ${ }^{2 \dagger}$, Luping Chang ${ }^{3}$, Chia-Lin Hsu ${ }^{3}$, Tzu-Hsuan Lai ${ }^{1}$, Fong-Lee Huang ${ }^{4}$ and Young-Ji Shiao $1,3,5,6^{*}$

\begin{abstract}
Background: The roles of caspase 3 on the kainic acid-mediated neurodegeneration, dendritic plasticity alteration, neurogenesis, microglial activation and gliosis are not fully understood. Here, we investigate hippocampal changes using a mouse model that receive a single kainic acid-intracerebral ventricle injection. The effects of caspase 3 inhibition on these changes were detected during a period of 1 to 7 days post kainic acid injection.

Result: Neurodegeneration was assessed by Fluoro-Jade B staining and neuronal nuclei protein (NeuN) immunostaining. Neurogenesis, gliosis, neuritic plasticity alteration and caspase 3 activation were examined using immunohistochemistry. Dendritic plasticity, cleavvage-dependent activation of calcineurin A and glial fibrillary acidic protein cleavage were analyzed by immunoblotting. We found that kainic acid not only induced neurodegeneration but also arouse several caspase 3-mediated molecular and cellular changes including dendritic plasticity, neurogenesis, and gliosis. The acute caspase 3 activation occurred in pyramidal neurons as well as in hilar interneurons. The delayed caspase 3 activation occurred in astrocytes. The co-injection of caspase 3 inhibitor did not rescue kainic acid-mediated neurodegeneration but seriously and reversibly disturb the structural integrity of axon and dendrite. The kainic acid-induced events include microglia activation, the proliferation of radial glial cells, neurogenesis, and calcineurin A cleavage were significantly inhibited by the co-injection of caspase 3 inhibitor, suggesting the direct involvement of caspase 3 in these events. Alternatively, the kainic acid-mediated astrogliosis is not caspase 3-dependent, although caspase 3 cleavage of glial fibrillary acidic protein occurred.

Conclusions: Our results provide the first direct evidence of a causal role of caspase 3 activation in the cellular changes during kainic acid-mediated excitotoxicity. These findings may highlight novel pharmacological strategies to arrest disease progression and control seizures that are refractory to classical anticonvulsant treatment.
\end{abstract}

Keywords: Epileptogenesis, Kainic acid, Neurodegeneration, Caspase 3, Gliosis, Neurogenesis, Hippocampus

\footnotetext{
* Correspondence: yshiao@nricm.edu.tw

${ }^{\dagger}$ Equal contributors

'Institute of Biopharmaceutical Science, National Yang-Ming University, Taipei

112, Taiwan

${ }^{3}$ Division of Basic Chinease Medicine, National Research Institute of Chinese

Medicine, Taipei 112, Taiwan

Full list of author information is available at the end of the article
} 


\section{Background}

Epileptogenesis is the process of epilepsy development which is characterized by recurrent seizures following an initial insult, such as status epilepticus (SE). This process requires intricate molecular, cellular and hippocampal network reorganization before the first spontaneous seizure occurs. The changes among epileptogenesis include neurodegeneration, neurogenesis, axonal sprouting, dendritic plasticity alteration, and gliosis [1-6].

Kindling is a commonly used model for the development of seizures and epilepsy. kainic acid (KA) is one of the most common chemoconvulsants used to create SE models of temporal lobe epilepsy (TLE). Hippocampal lesions in this model are similar to the hippocampal sclerosis observed in humans with TLE [7-10]. KA is commonly administered systemically to cause sustained neuronal depolarization and seizure generation with a high mortality rate [11]. To reduce mortality, KA may be alternatively injected into lateral ventricle [12].

Hippocampus is an important structure in the pathophysiology of epilepsy. Principal neurons and interneurons are two major groups of neurons in the hippocampal cortex. Most of the principal neurons, such as pyramidal neurons, form excitatory synapse on the remote neurons, whereas the interneurons form inhibitory synapses on principal neurons and other interneurons to prevent the generation of convulsions. Histologically, hippocampal cortex can be divided into CA1-CA4 fields, which contains small pyramidal neurons. The circulation of nerve impulses is formed between CA1-CA4 and enthorinal cortex [13]. The initial limbic seizures increase hippocampal neurogenesis from radial glial cells $[14,15]$. Prolonged seizures, however, result in aberrant migration and connection of newly born neurons $[16,17]$ and lead to recurrent excitatory circuitry [18]. Conversely, chronic recurrent spontaneous seizures are associated with substantially reduced neurogenesis that coexists with learning and memory impairments [19].

The involvement of astrogliosis in epileptogenesis may be attributable to altered dynamic signaling between neurons, astrocytes and several astrocytic membrane proteins [20]. SE may stimulate reactive astrocytes to proliferate and express more glial fibrillary acidic protein (GFAP) [21], which is associated with altered glutamate uptake and calcium signaling [22]. Morphologically, SE causes thickening and overlapping of astroglial processes and loss of astroglial domains [23]. Nevertheless, the molecular link between initial insults and later changes including neurodegeneration, neurogenesis, synaptic plasticity alteration, and astrogliosis, remains to be elucidated.

Caspase 3 is implicated in the regulation of synaptic plasticity alteration [24], cytoskeletal remodeling [25], and the differentiation of glial cells [26] and stem cells [27]. Notably, localized caspase 3 activity that causes synaptic failure has been observed in vitro [28], but the molecular mechanism linking caspase 3 activity to synaptic loss in epileptogenesis is unclear. Furthermore, although caspase 3-mediated cleavage of astrocytic GFAP has been previously detected in reactive or degenerating astrocytes [27,29], the effects of caspase 3 on reactive astrocytes or radial glial cells during epileptogenesis require further investigation. To verify the role of caspase 3 in neurodegeneration, neurogenesis, synaptic plasticity, and astrogliosis during the early phase of epileptogenesis, the specific inhibitor of caspase 3 was applied onto an SE-induced epilepsy model which kainic acid (KA) is administered via intracerebral ventricle (icv) injection. Our data suggests that caspase 3 activity is crucial for cellular alterations during epileptogenesis.

\section{Methods}

\section{Animals and treatment}

The Institutional Animal Care and Use Committee at the National Research Institution of Chinese Medicine approved the animal protocol (IACUC No: P-99-18). The outbred CD-1 (ICR) mice are selected for this study due to that they are vulnerable to neurodegeneration [30]. Six week-old male CD-1 mice were housed for 1 week under standard conditions at $25 \pm 2^{\circ} \mathrm{C}$ with a 12-h light/dark cycle and were allowed free access to water and standard chow. Administration (icv) of KA (Merck) was performed unilaterally on male CD-1 mice (6 weeks old). The mice were anesthetized with intraperitoneal (ip) chloral hydrate (Sigma; $0.4 \mathrm{~g} / \mathrm{kg}$ body weight, maintained with $0.1 \mathrm{~g} / \mathrm{kg}$ hourly) and fixed into a stereotaxic apparatus. The dorsal surface of the skull was exposed with a midline incision, and a burr hole was drilled at the following coordinates: anteroposterior, $0.22 \mathrm{~mm}$ caudal to bregma and $1 \mathrm{~mm}$ right lateral to midline. A $10-\mu \mathrm{l}$ Hamilton syringe fitted with a 25-gauge needle and filled with KA alone or combined with caspase 3 inhibitor (DEVD-CHO, Insolution Caspase-3 inhibitor I, cell permeable, $1 \mathrm{mg} / 100 \mu \mathrm{l}$, Merck) solution in saline was placed over the burr hole and lowered $2.5 \mathrm{~mm}$ into the surface of the brain, and the solution was injected at a rate of $0.2 \mu \mathrm{l} / \mathrm{min}$. The needle was then left in place for 2 min before it was slowly retracted. Control animals were injected with saline. The first seizure lasting for at least half hour was used to identify the occurrence of SE. The proper KA amount for KA-icv-injection experiment was determined by the profile of KA-induced seizure after the mice to regain consciousness from anesthetization. The seizure profile was determined according to Racine's scale [31]: stage 0 , no response or behavior arrest; stage 1, chewing or facial twitches; stage 2, chewing and head nodding or wet dog shakes; stage 3, unilateral forelimb clonus; stage 4, bilateral forelimb clonus and rearing; stage 5, bilateral forelimb clonus, 

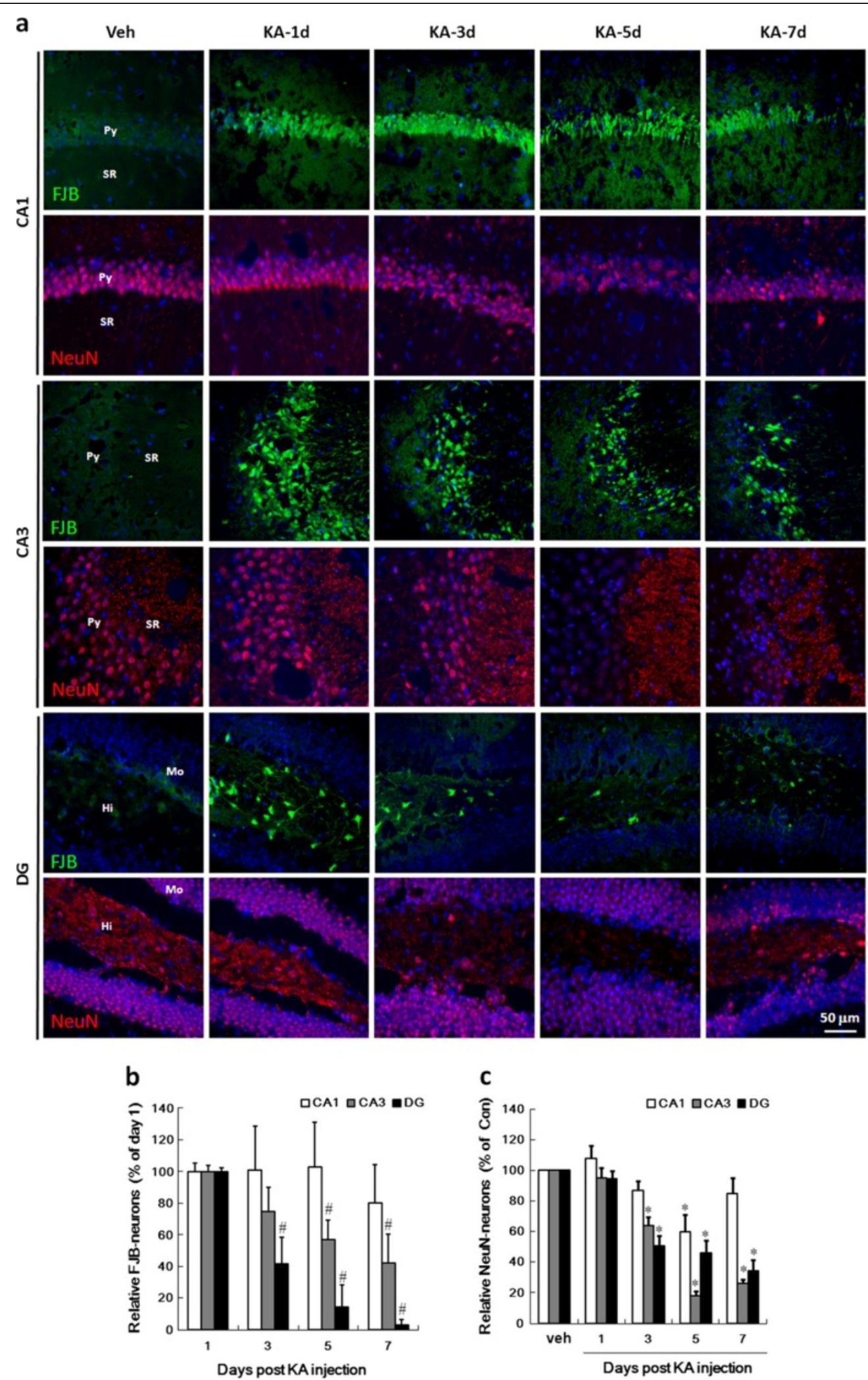

Figure 1 (See legend on next page.) 
(See figure on previous page.)

Figure 1 The neurodegeneration in the hippocampus of the KA-icv-injected mice. CD-1 mice received KA-icv-injections and were sacrificed at day $1,3,5$, and 7 post $K A$-injection (KA-d1, KA-d3, KA-d5, and KA-d7). For control, the mice were sacrificed at day 7 post vehicle-injection (veh). The neurodegeneration in the ipsilateral side of CA1, CA3, and DG was examined by FJB-staining (FJB, green) and immunostaining with anti-NeuN (NeuN, red) antibody. Cell nuclei were stained with Hoechst 33258 (blue). Panel (a) shows the representative fluorescent images of the ipsilateral side of CA1, CA3 and DG. The location of pyramidal layer (Py), striatum radiatum (SR). Molecular layer (Mo), and Hilus (Hi) are indicated in the images of the left lane of the panels. The number of FJB-positive (b) and NeuN-positive (c) neurons in the ipsilateral side of CA1 (white columns), CA3 (grey columns), and DG (black columns) were calculated using MetaMorph software. The results are the mean \pm S.D. from 8 images. The data in panel (b) are the percentages relative to the day 1 post injection. The data in panel (c) are the percentages relative to the vehicle injection. Significant differences between day 1 post injection and day 3, 5 and 7 post injection in panel (b) are indicated by \#, P $<0.001$. Significant differences between vehicle injection and KA injection in panel (c) are indicated by *, $P<0.001$.

rearing and falling. The proper KA amount was then determined as $2 \mu \mathrm{l}(0.4 \mu \mathrm{g})$. The proper caspase 3 inhibitor amount was set as $1 \mu \mathrm{l}(10 \mu \mathrm{g})$ base on the previous study $[32,33]$.

\section{Tissue processing}

At day 1, 3, 5, and 7 post KA-injection and day 7 post vehicle-injection as control, mice were deeply anesthetized with chloral hydrate and perfused through the heart with $30 \mathrm{ml}$ of saline followed by $30 \mathrm{ml}$ of fixative solution containing $4 \%$ formaldehyde in saline. The brain was removed, post-fixed in $4 \%$ formaldehyde for $18 \mathrm{~h}$ at $4^{\circ} \mathrm{C}$ and cryoprotected in $30 \%$ sucrose solution in $0.1 \mathrm{M}$ phosphate-buffered saline (PBS). A cryostat was used to cut 30- $\mu \mathrm{m}$ coronal sections through the dorsal hippocampus, which were collected serially in PBS.

\section{Fluoro-Jade $B$ staining}

Fluoro-Jade B (FJB) has been used for the histological staining of degenerating neurons [34,35]. For staining the KA-mediated neurodegeneration, brain sections were mounted on polylysine-coated glass slides and fully dried. The sections were rehydrated by immersion in $100 \%$ ethanol, $70 \%$ ethanol, and distilled water for $1 \mathrm{~min}$ each. The slides were then transferred to a solution of $0.06 \%$ potassium permanganate for $15 \mathrm{~min}$ on a horizontal shaker, rinsed for $1 \mathrm{~min}$ in distilled water, and then incubated in a solution of $0.0004 \%$ FJB (Invitrogen) for $20 \mathrm{~min}$ at room temperature. The sections were rinsed 3 times for $1 \mathrm{~min}$ each in distilled water, and the slides were fully dried. The slides were cleared by immersion in xylene for at least $1 \mathrm{~min}$ before cover slipping. Digital images were acquired using a confocal laser scanning microscope (Leica CS SP, Waltlar, Germany and Zeiss LSM780, Jena, Germany) with excitation at $488 \mathrm{~nm}$ and emission at $525 \mathrm{~nm}$.

\section{Immunohistochemistry}

Brain sections were incubated in blocking solution (PBS containing 5\% normal donkey serum, $2 \%$ Triton X-100, $0.02 \%$ bovine serum albumin, BSA) overnight at $4^{\circ} \mathrm{C}$ and left overnight at $4{ }^{\circ} \mathrm{C}$ in staining solution (PBS containing $5 \%$ normal goat serum, $0.25 \%$ Triton X-100, $0.02 \%$ BSA) with primary antibodies, including mouse monoclonal antibody to GFAP (Invitrogen); rabbit polyclonal antibody to doublecortin (Abcam); goat monoclonal antibody to ionized calcium-binding adaptor molecule-1 (Iba-1, Abcam); and rabbit polyclonal antibody to active caspase 3 (R\&D Systems). Sections were then incubated in staining solution containing Hoechst33258 (Invitrogen, $2 \mu \mathrm{g} / \mathrm{ml}$ ), Fluorescein isothiocyanate-conjugated donkey anti-mouse IgG and RRX-conjugated donkey anti-rabbit IgG or cy5-conjugated donkey anti-goat $\operatorname{IgG}(1: 200$; Jackson ImmunoResearch) in the dark overnight at $4^{\circ} \mathrm{C}$. Sections were then washed in PBS and mounted with Aqua Poly/Mount (Polyscience Inc., Warrington, PA, USA).

\section{Quantitative immunofluorescence analysis}

All analyses were calculated within a field $\left(250 \times 250 \mu \mathrm{m}^{2}\right)$ of Cornu Ammonis (CA)1, CA3 and dentate gyrus (DG) of 3 series hippocampal slices every brain in a range of bregma -1.34 to -1.49 . The numbers of FJB-positive neurons were manually counted. Because the control sample did not have any degenerating cells, the number of FJBpositive cells at day 1 post KA injection was defined as $100 \%$ degeneration, and the values from other time points were calculated as the percentage relative to it. MetaMorph Image System and Microsoft Excel were used to assess the images and quantify the relative florescent intensity. The grayscale values relative to the highest concentration of fluorescence and the lack of fluorescent marker in the section were defined as $100 \%$ and $0 \%$ density values, respectively. The expression of GFAP and Iba-1 was calculated from the immunoreactivity (IR) of each protein that displayed as the optical density (arbitrary unit) of each image.

\section{Postsynaptic density (PSD) preparation}

The brain was rapidly dissected, and the hippocampus was homogenized in 10 volumes of $\mathrm{H}$-Buffer $(320 \mathrm{mM}$ sucrose, $2 \mathrm{mM}$ EDTA, $20 \mathrm{mM}$ Tris- $\mathrm{HCl}$ [pH 7.4], $1 \mathrm{mM}$ PMSF, $5 \mu \mathrm{g} / \mathrm{ml}$ leupeptin, $5 \mu \mathrm{g} / \mathrm{ml}$ aprotinin) with 30 strokes with a tight-fitting glass Dounce tissue grinder (5 ml, Wheaton). The homogenate was centrifuged at $1,000 \times g$ for $10 \mathrm{~min}$, and the resulting supernatant was centrifuged at $13,000 \times g$ for $20 \mathrm{~min}$. The pellet was 


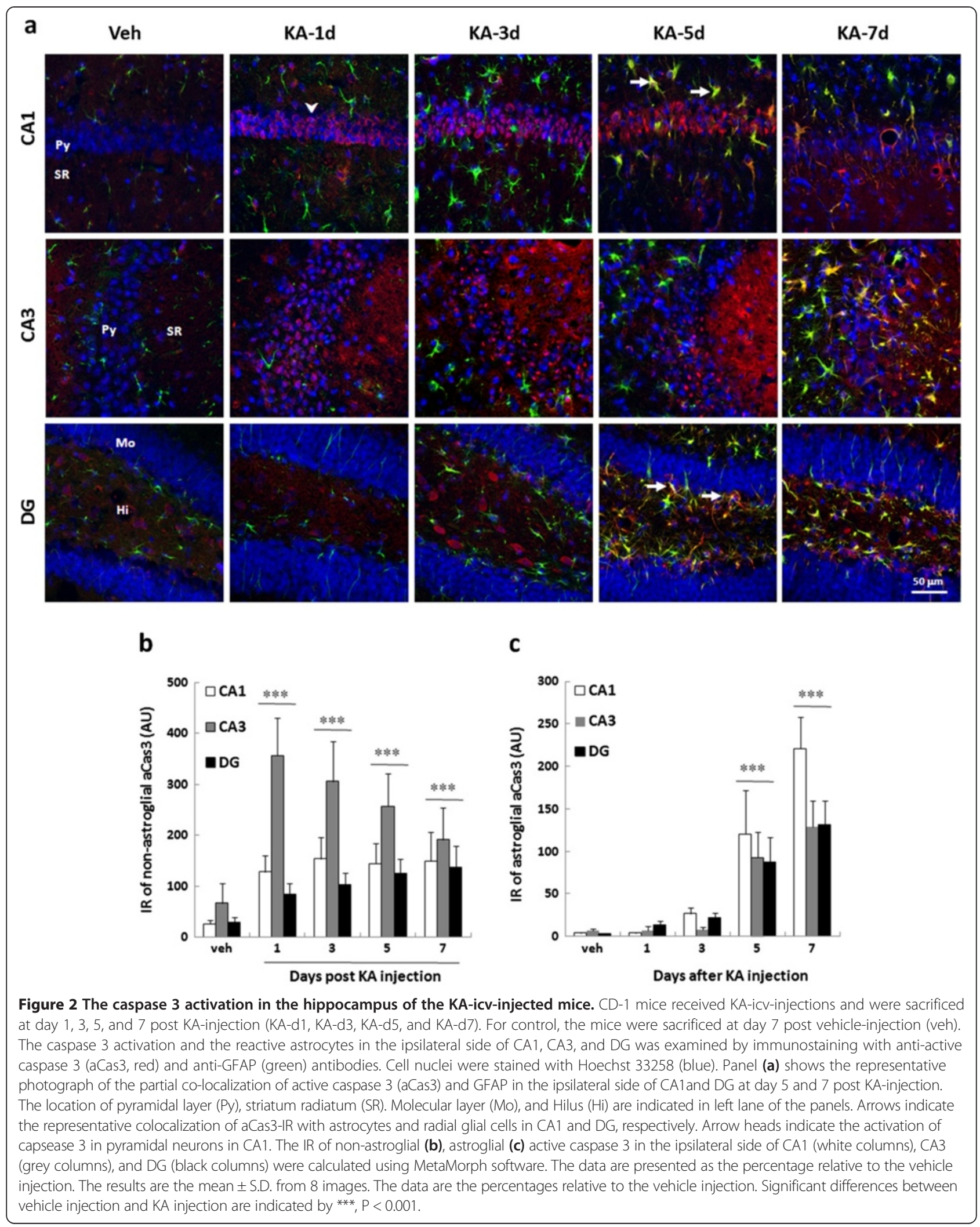




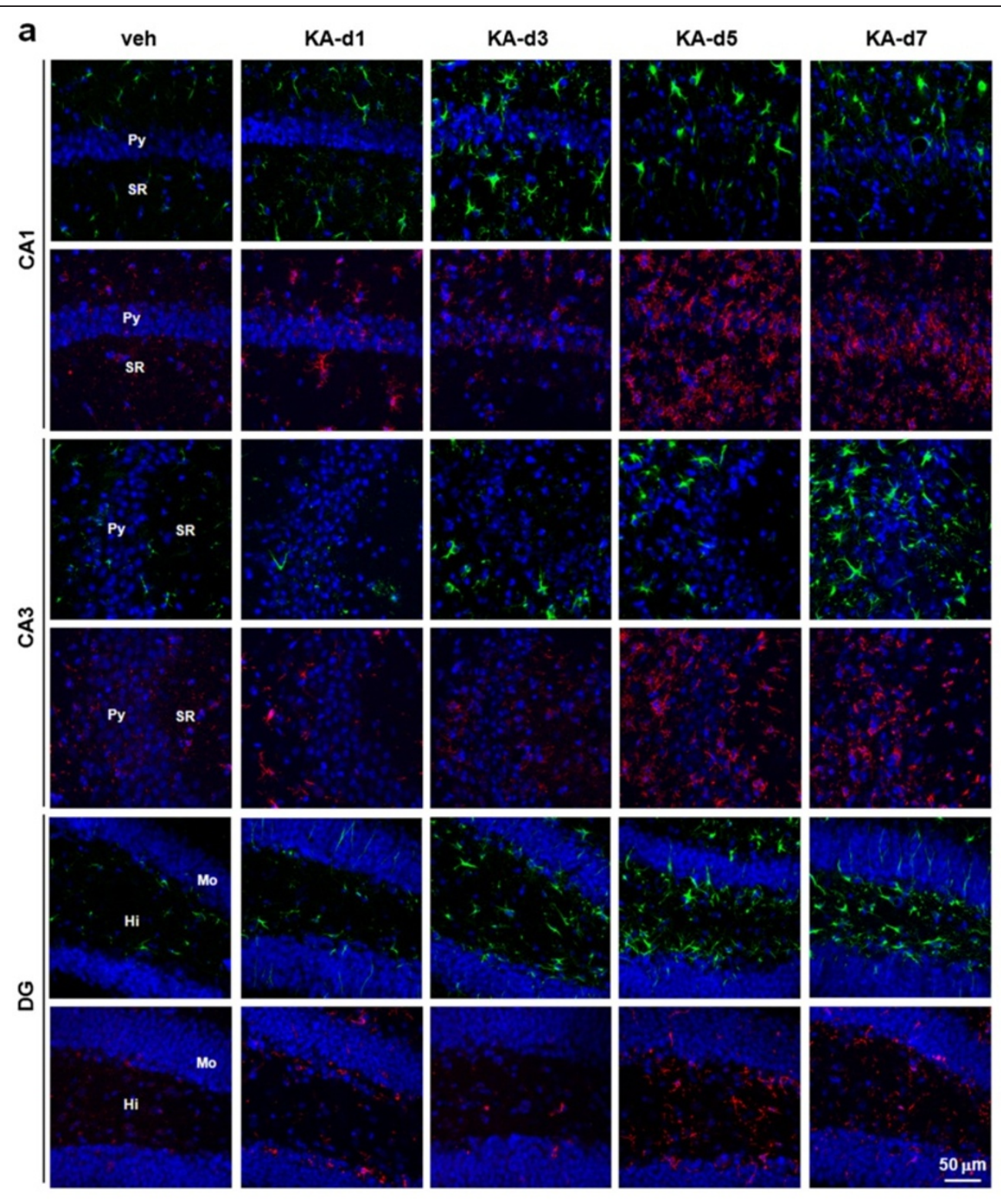

b

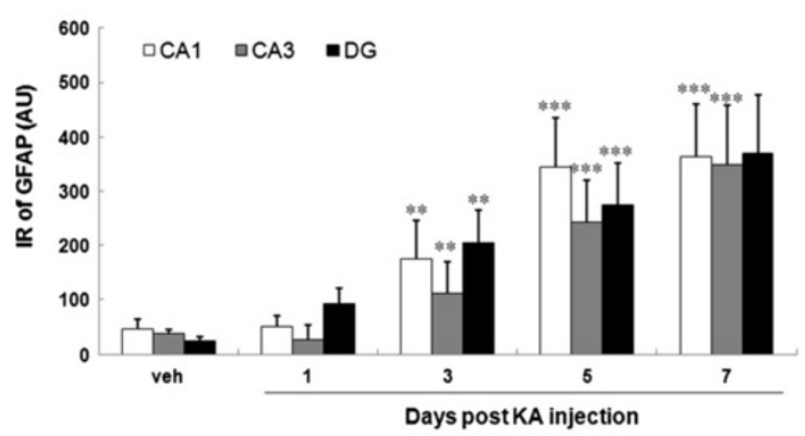

C

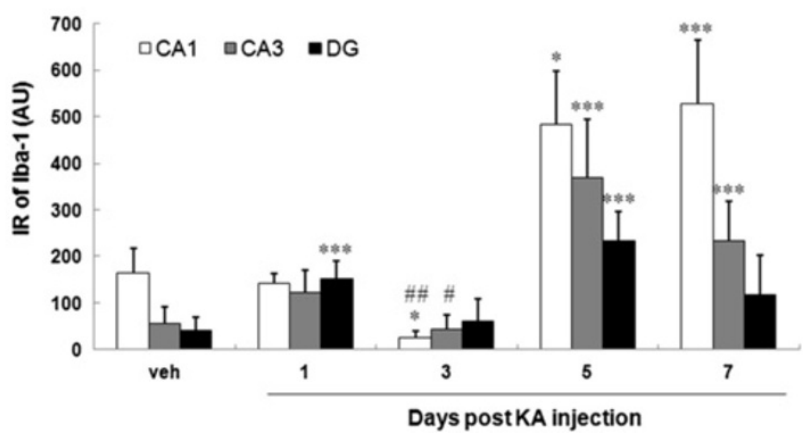

Figure 3 (See legend on next page.) 
(See figure on previous page.)

Figure 3 The microglial activation in the hippocampus of KA-icv-injected mice. CD-1 mice received KA-icv-injections and were sacrificed at day 1, 3, 5, and 7 post KA-injection (KA-d1, KA-d3, KA-d5, KA-d7). For control, the mice were sacrificed at day 7 post vehicle-injection (veh). The microglial activation in the ipsilateral side of CA1, CA3, and DG was examined by immunostaining with anti-lba-1 (red) and anti-GFAP (green) antibodies. Cell nuclei were stained with Hoechst 33258 (blue). The representative images of the ipsilateral side of CA1, CA3 and DG area are shown (a). The location of pyramidal layer (Py), striatum radiatum (SR). Molecular layer (Mo), and Hilus (Hi) are indicated in the left lane of the panels. The IR of GFAP (b) and Iba-1 (c) in $250 \mu \mathrm{m} \times 250 \mu \mathrm{m}$ field in CA1 (white columns), CA3 (gray columns) and DG (black columns) were calculated. The results are the mean \pm S.D. from 8 images. Significant differences between the control (veh) and the KA injection are indicated by ${ }^{*}, \mathrm{P}<0.05 ;{ }^{* *}, \mathrm{P}<0.01 ;{ }^{* * *}, \mathrm{P}<0.001$. Significant differences between day 1 post KA injection and day 3 post $\mathrm{KA}$ injection in panel $d$ are indicated by \#, $\mathrm{P}<0.05 ; \# \#, \mathrm{P}<0.01$.

resuspended in an equal volume of TET buffer (1\% Triton-X 100, 2 mM EDTA, 20 mM Tris-HCl [pH 7.4], $1 \mathrm{mM}$ PMSF, $5 \mu \mathrm{g} / \mathrm{ml}$ leupeptin, $5 \mu \mathrm{g} / \mathrm{ml}$ aprotinin) and agitated for $1 \mathrm{hr}$ at $4^{\circ} \mathrm{C}$. The extracts were centrifuged at $100,000 \times g$ for $1 \mathrm{~h}$. The resulting pellet was resuspended in 0.1 volume of buffer containing 1\% SDS, 2 mM EDTA, and $20 \mathrm{mM}$ Tris- $\mathrm{HCl}$ (pH 7.4). Then, 0.9 volume of TET buffer was added, and the extracts were agitated for $1 \mathrm{hr}$ at $4^{\circ} \mathrm{C}$, sonicated and incubated on ice for $20 \mathrm{~min}$. The samples were centrifuged at $11,500 \times g$ for $10 \mathrm{~min}$, and the protein concentration of the resulting supernatant was determined.

\section{Immunoblots}

For Western blot analysis, samples (6 $\mu \mathrm{g}$ protein) were separated by sodium dodecyl sulfate-polyacrylamide gel electrophoresis ( $15 \%$ gels) and were then transferred to PVDF membranes. The primary antibodies used were as follows: mouse monoclonal antibody to GFAP (BD Bioscience), PSD-95 (Millipore), actin (Invitrogen), rabbit polyclonal antibody to glutamate receptor 1 (GluR1), NMDA receptor 1 (NR1), and calcineurin A (CN-A) (Millipore). The secondary antibodies were anti-rabbit IgG antibody conjugated with horseradish peroxidase (HRP; GE Healthcare) and anti-mouse IgG antibody conjugated with HRP (Jackson ImmunoResearch). Enhanced chemiluminescence detection reagents (GE Healthcare) were used for detection. Bands were quantified using Fujifilm LAS-3000 Luminescent Image Analyzer (Tokyo, Japan).

\section{Statistical analysis}

The results are expressed as the mean \pm standard deviation (S.D.) and were analyzed by analysis of variance (ANOVA) with post-hoc Bonferroni multiple comparisons tests.

\section{Results}

The neurodegeneration occurred in the hippocampus of the KA-icv-injected mice

To explore the neurodegenerative process after KAinjection, FJB staining of hippocampus was performed (Figure 1a, b). The results show that the neurons were quickly labeled by FJB (FJB-neurons) at day 1 post KA- injection. The major FJB-neurons include the pyramidal neurons in CA1/3, and the interneurons in DG-hilus. During the period of day 3 to 7 post KA-injection, the number of the FJB-neurons was reduced time-dependently. The decrease rate of the FJB-neurons in DG-hilus was faster than that in CA3. Alternatively, the number of FJBneurons in CA1 is not significantly altered (Figure $1 \mathrm{~b}$ ). We use NeuN as another marker to verify the neurodegeneration. Our result observe a prominent loss of NeuN in CA3 and DG beginning at day 3 post KA-injection, and a transient but reversible loss at day 5 post KA-injection in CA1 (Figure 1a and 1c).

\section{Caspase 3 activation occurred in both neurons and glial cells in the hippocampus of KA-icv-injected mice}

To verify the contribution of the caspase-dependent apoptosis on KA-mediated neurodegeneration, we performed immunostaining by anti-active caspase 3 antibody (Figure 2). The results show that caspase 3 may be activated in neurons and glial cells successively. During the period of day 1 to 3 post KA-injection, caspase 3 was activated in the cell body of pyramidal neurons in both CA1 and CA3. In the CA3, the colocalization of active caspase 3 with the neurites of pyramidal neurons was observed in the stratum radiatum. In DG, active caspase 3 was found in the hilar interneurons at day 3 post KA-injection (Figure 2a, 2b). During the period of day 5 to 7 post KA-injection, active caspase 3 was observed in astrocytes and the radial glial cells in subgranular zoon (SGZ) of DG (Figure 2a, 2c).

\section{Astrogliosis and microglial activation is promoted in the hippocampus of KA-icv-injected mice}

To assess hippocampal astrogliosis and microglial activation, we performed immunostaining using anti-GFAP and anti-Iba-1 antibodies (Figure 3a). Astrocytes in the hippocampus of control mice displayed small somata with thin processes morphologies. After KA-injection, the cell bodies of astrocytes were enlarged, and their cell processes were thickened. GFAP immunoreactivity (IR) was significantly increased at day 3 post KA-injection and with the highest expression at day 7 post KA-injection (Figure 3b). The relative IR per field of view of GFAP increased by 7.1-, 13.4- and 14.5-fold of the vehicle-injected 


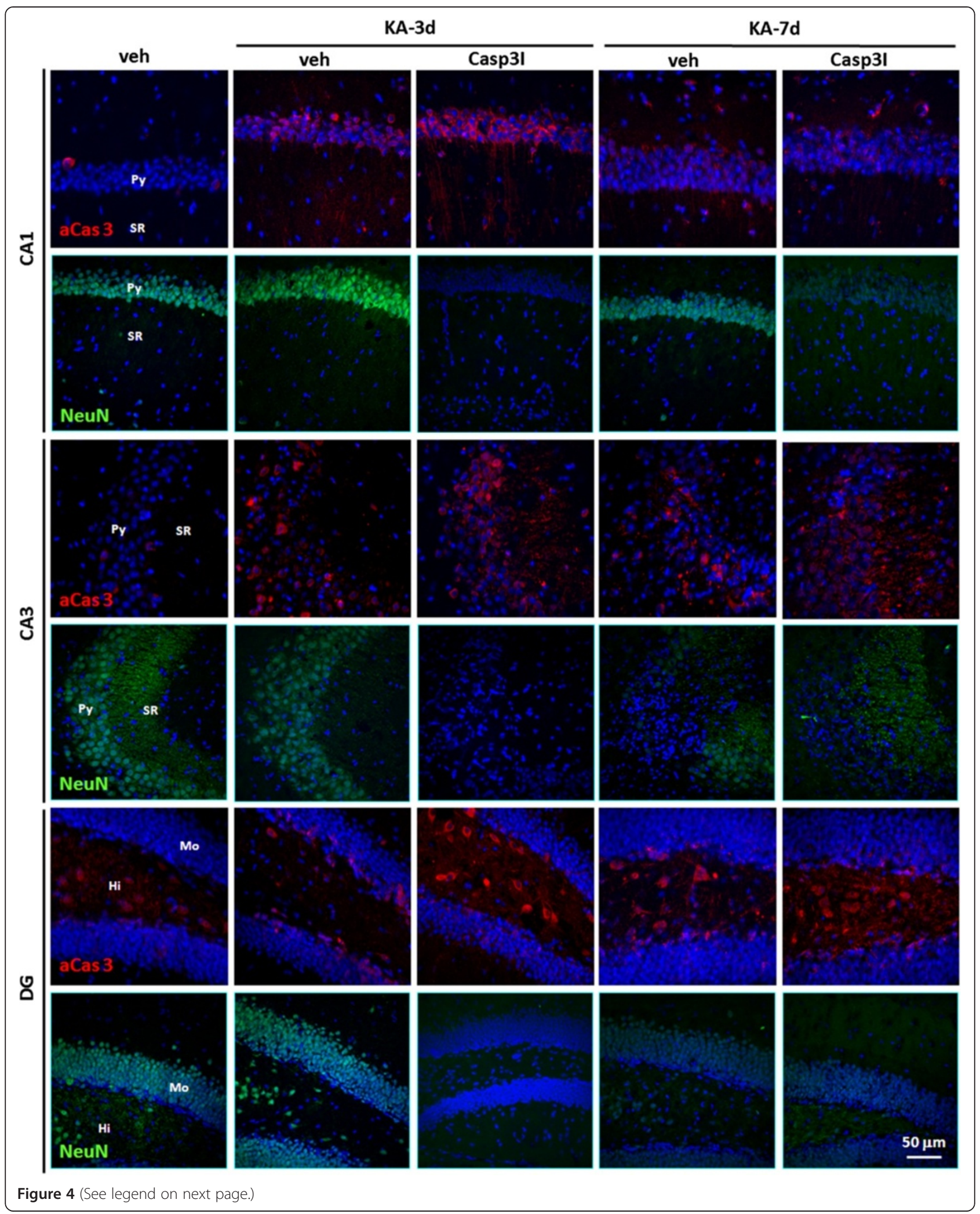


mice in CA1, CA3, and DG, respectively. The number of GFAP-stain radial glial cells in SGZ is also increased after KA-injection.

Microglia in the hippocampus of control mice displayed ramified morphologies. After KA injection, the cell bodies of a microglia were enlarged, and their cell processes were thickened. However, the pattern of cell number increase of microglia was different as comparing with astrocytes (Figure 3a). The increase of Iba-1 IR was biphasic after KA-injection (Figure 3c). The first phase occurred at day 1 post KA-injection, and the second phase peaked at day 5 post KA injection. Between these two peaked phases, Iba-1 IR fall in a trough at day 3 post KA-injection. In the second phase, the IR increased by 19.7-, 8.6- and 4.0-fold of that at day 3 post KAinjection in CA1, CA3, and DG, respectively.

\section{Caspase 3 activation involves in neurite structure alteration but not in neurodegeneration}

The caspase 3 inhibitor (insolution Casapase-3 Inhibitor I, Merck) was then employed to elucidate the role of caspase 3 activation on KA-mediated neurodegeneration. The inhibiting target of caspase 3 inhibitor is the activity of the active caspase 3 , but not the activation of caspase 3. Therefore, after co-injection of KA and caspase 3 inhibitor, the biphasic activation of caspase 3 was not altered by caspase 3 inhibitor (Figure 4). NeuN was completely loss at day 3 post KA-injection, which did not occur as KA injection alone. The structural integrity of axon and dendrite was further examined by immunostaining using anti-MAP-2 and anti-tau antibody, respectively [36]. The results indicate that the structural integrity of axon and dendrite is mildly affected after KA-injection. The co-injection of KA and caspase 3 inhibitor, however, seriously disturb the structural integrity of axon and dendrite at day 3 post KA-caspase 3injection in CA1, CA3 and DG (Figure 5). The disturbance is recovered at day 7 post KA-caspase 3-injection.

\section{Caspase 3 activation is involved in the GFAP cleavage in the hippocampus of KA-icv-injected mice}

GFAP is the building block of astroglial intermediate filaments. Levels of GFAP and its cleavage have been related to reactive gliosis and astroglial apoptosis, and may be also related to differentiation of the radial glial cells.
Therefore, we assessed hippocampal GFAP levels by immunoblotting (Figure 6). After KA-treatment, the level of GFAP was significantly increased at day 3, 5, and 7 post KA-injection. Full length GFAP (52 kDa) was progressively cleaved into smaller fragments time-dependently (Figure 6a). GFAP fragments of $45 \mathrm{kDa}$ at day 1 post KAinjection and $40 \mathrm{kDa}$ at day 3 post $\mathrm{KA}$-injection were detected. The level of $45 \mathrm{kDa}$ fragment increased from $4.61 \pm 1.68 \%$ in the control to $82.06 \pm 12.84 \%, 116.69 \pm$ $30.81 \%, 124.58 \pm 27.29 \%$ and $149.97 \pm 36.75 \%$ of the control at day $1,3,5$, and 7 post KA-injection, respectively. The level of $40 \mathrm{kDa}$ fragment increased to $3.59 \pm 1.68 \%$, $31.63 \pm 25.20 \%, 52.58 \pm 21.65 \%$ and $87.28 \pm 38.79 \%$ of $52 \mathrm{kDa}$ GFAP in the control at day 1, 3, 5, and 7 post KA-injection, respectively. The co-injection of KA and caspase 3 inhibitor inhibit $40 \mathrm{kDa}$ fragment production at day 7 post KA-caspase 3 -injection (Figure 6b).

\section{Neuroplasticity is modulated in the hippocampus of KA-icv-injected mice}

Immunoblot analysis of PSD-proteins from the brain homogenates after KA-injection showed a time-dependent decrease of the level of PSD-95, NMDA receptor (NR)1, glutamate receptor (GluR)1, GluR2 and SAP-102 from day 1 to 5 post KA-injection, which are partially recovered at day 7 post KA-injection (Figure 7a). To compare the synaptic removal extent of different PSD proteins, the decrease of NR1, GluR1, GluR2 and SAP-102 are compared to that of PSD-95. The result shows that the ratio of NR1/PSD-95 and SAP-102/PSD-95 is significantly decreased during the period of day 1 to 7 post KA-injection. The ratio of GluR1/PSD-95 and GluR2/ PSD-95 is significantly decreased and increased at day 1 and day 5 post KA-injection, respectively (Figure 7a).

Synaptic removal of $\alpha$-amino-3-hydroxy-5-methyl-4isoxazolepropionic acid receptors (AMPARs) has been reported to be mediated by calcineurin $\mathrm{A}(\mathrm{CN}-\mathrm{A})$ which is proteolytically activated by caspase 3 . Therefore, the KA injection-mediated proteolysis of $\mathrm{CN}-\mathrm{A}$ were examined (Figure $7 \mathrm{~b}$ ). The result shows that the active form CN-A (36 kDa fragment) increased to $415.09 \pm 59.33$ and $387.37 \pm 15.84 \%$ of the vehicle injection at day 5 and 7 post KA-injection, respectively. To verify the involvement of caspase 3 on KA-induced proteolysis of $\mathrm{CN}-\mathrm{A}$, caspase 3 inhibitor were co-injected with $\mathrm{KA}$ and the 


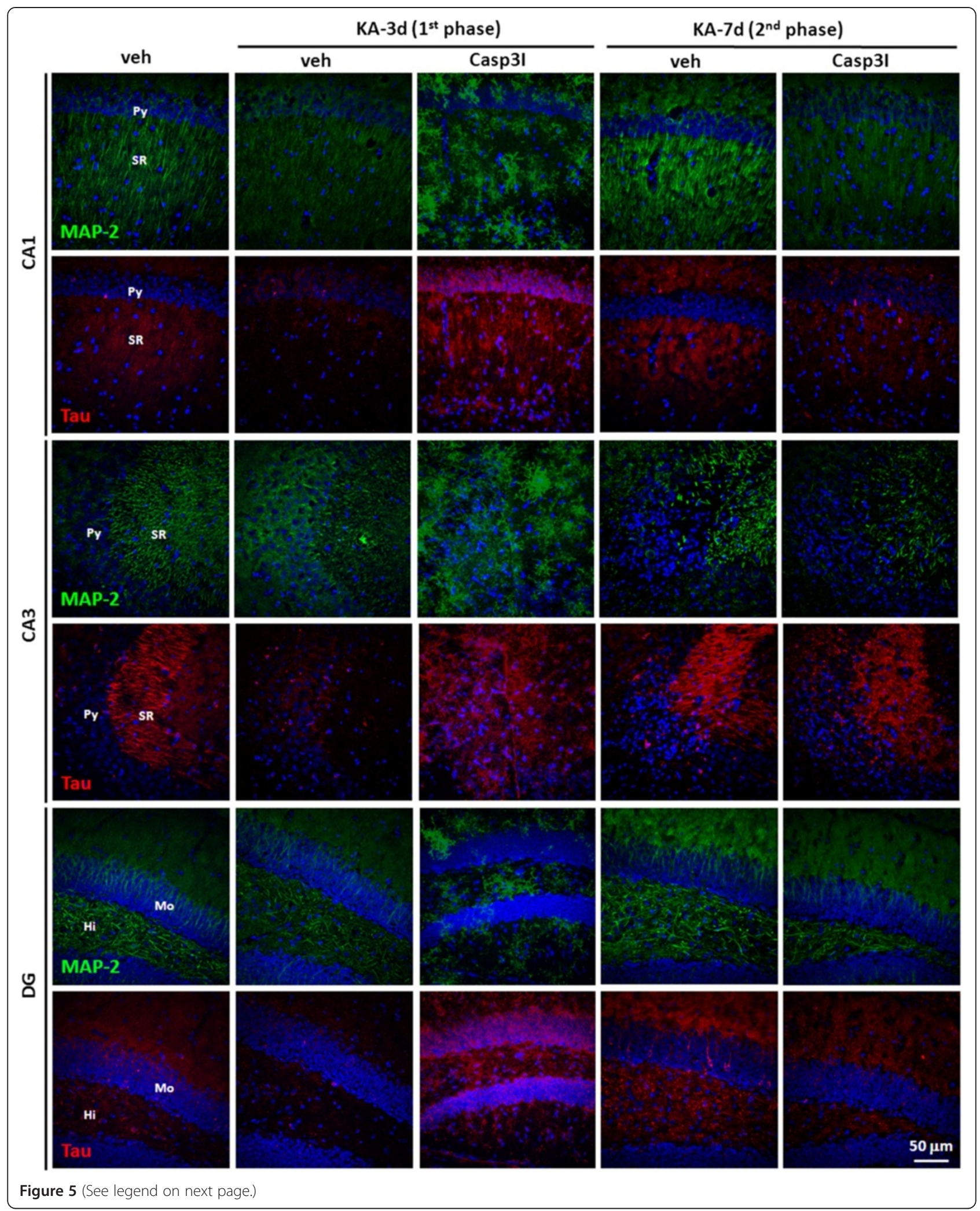



KA-injection (KA-d3 and KA-d7). For control, the mice were sacrificed at day 7 post vehicle-injection (veh). The neurites in the ipsilateral side of CA1 was examined by immunostaining with anti-MAP-2 (green) and anti tau-protein (Tau, red) antibodies. Cell nuclei were stained with Hoechst 33258 (blue). The representative fluorescent images of the ipsilateral side of CA1 are shown. The location of pyramidal layer (Py), striatum radiatum (SR). Molecular layer (Mo), and Hilus (Hi) are indicated in the left lane of the panels.

result shows that the level of active form $\mathrm{CN}-\mathrm{A}(36 \mathrm{kDa}$ fragment) at day 7 post KA-injection is significantly decreased (Figure 7c).

\section{Neurogenesis is significantly promoted in the hippocampus of KA-icv-injected mice}

We hypothesized that the temporal- and spatial-dependent decline of FJB-positive signal in DG may be attributable to neurogenesis in SGZ. Therefore, we assessed newly born granular neurons and radial glial cells in the SGZ by immunostaining using anti-doublecortin (DCX) and antiGFAP antibody, respectively. The result shows that the number of DCX-positive newly born neurons and radial glial cells in SGZ are increased after KA injection
(Figure 8a and 8b). Both newly born neurons and radial glial cells are increased in the period of day 1 to 7 post KA-injection (Figure 8b).

\section{Caspase inhibition prevents the promotion of neurogenesis and microglial activation, but not astrogliosis, in the hippocampus of KA-icv-injected mice} The above results indicate that KA injection promotes caspase 3 activation and enhances neurogenesis, microglial activation, proliferation of radial glial cells and astrogliosis in the hippocampus of mice. We thus examine the role of caspase 3 activation at day 7 post KA-injection due to that time point presented all four events of neurogenesis, microglial activation, proliferation of radial glial cells

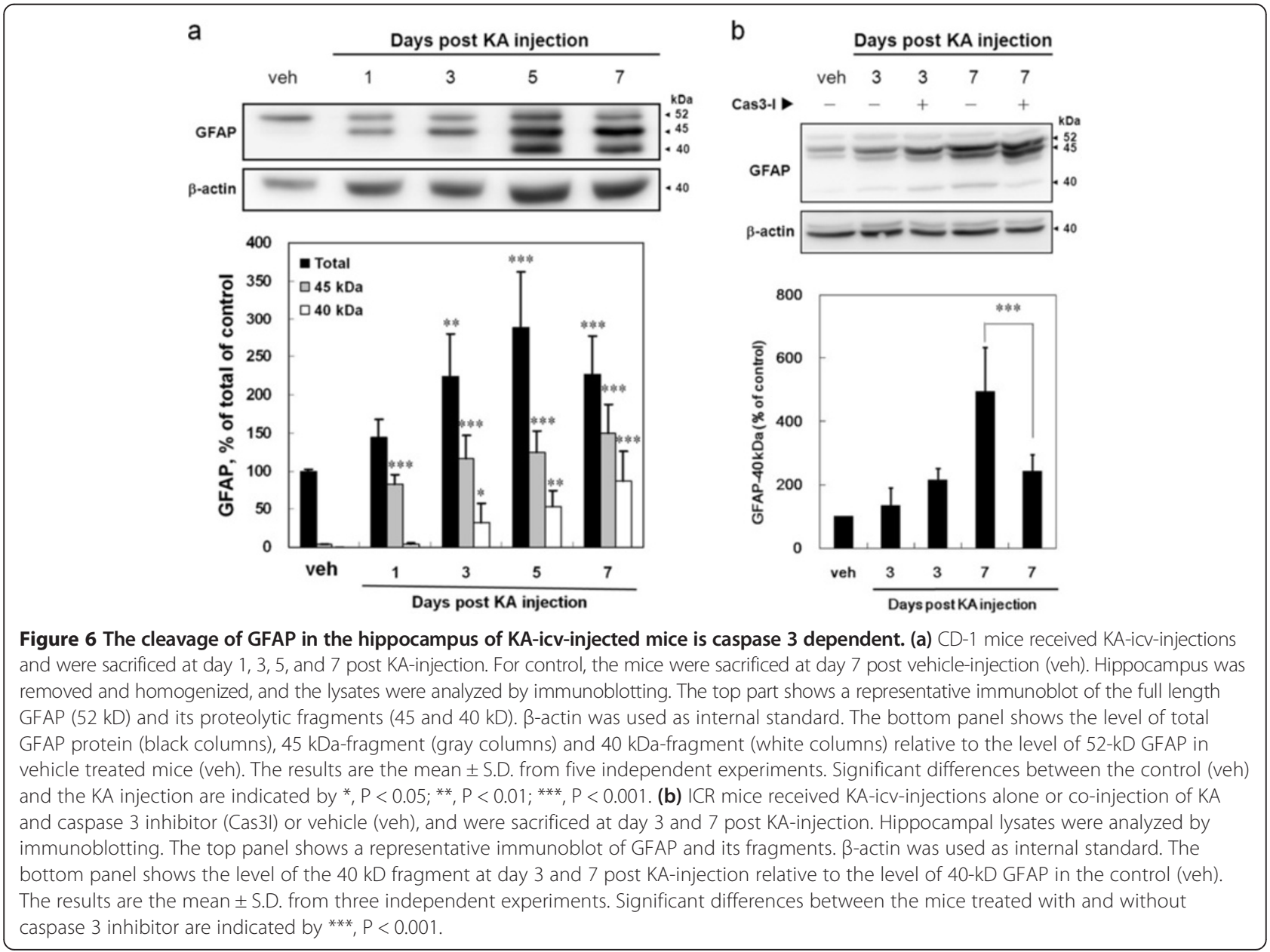



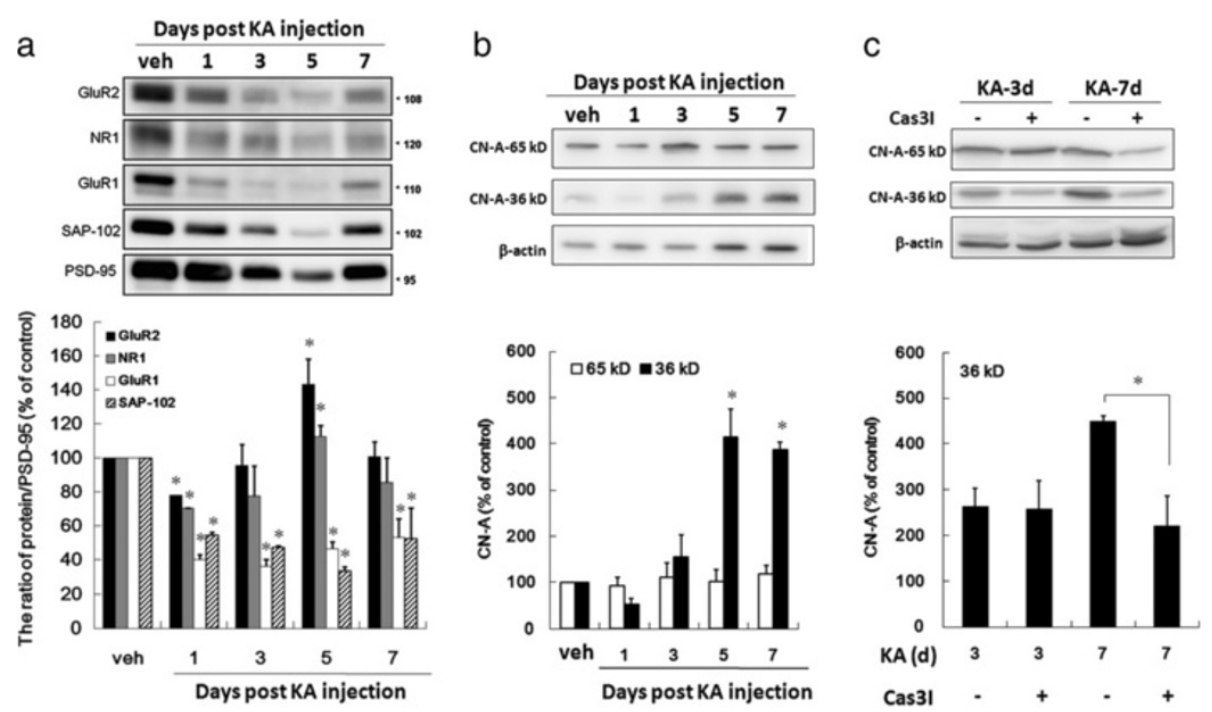

Figure 7 The alteration of the neuroplasticity-related proteins in the hippocampus of KA-icv-injected mice is caspase 3 dependent. CD-1 mice received KA-icv-injections and were sacrificed at day 1, 3, 5, and 7 post KA-injection. For control, the mice were sacrificed at day 7 post vehicle-injection (veh). Hippocampus The homogenate and PSD domain of hippocampus were prepared. The GluR2, GluR1, NR-1 and SAP-102 of PSD domain (a) and CN-A of total hippocampal homogenate (b) were analyzed by immunoblotting. (c) CD-1 mice received KA-icv-injections alone or co-injection of KA and caspase 3 inhibitor (Cas3l) or vehicle (veh), and were sacrificed at day 3 or 7 post KA-injection (KA-d3 and KA-d7). Hippocampal lysates were analyzed by immunoblotting. PSD-95 and $\beta$-actin were used as internal standard for (a) and (b, c), respectively. The top part is the representative immunoblots. The bottom part in (a) is the ratio of proteins/PSD-95 relative to the ratio of the control (veh). The bottom part in (b) and (c) show the percentage of the level of $65 \mathrm{kD}$ (open circles) and $36 \mathrm{kD}$ (closed circles) relative to the level of $65 \mathrm{kD}$ in the control (veh). Results are mean \pm S.D. from five independent experiments. Significant differences between the control (veh) and KA injection in $(\mathbf{a}, \mathbf{b})$ are indicated by ${ }^{*}, P<0.001$. Significant differences between the mice injected with and without caspase 3 inhibitor in (c) are indicated by $*, P<0.001$.

and astrogliosis. The suprapyramidal blade of granular layer of DG was triple-immunostained using anti-DCX, anti-Iba1 and anti-GFAP antibodies to determine the newly born neurons, microglia, astrocytes and radial glial cells, respectively (Figure $8 \mathrm{c}$ and $8 \mathrm{~d}$ ). The result showed that the KAinjection-mediated cell number increase of radial glial cells, newly born neurons, and microglia are diminished by caspase 3 inhibitor. The KA-injection-mediated astrogliosis is however not affected by caspase 3 inhibitor.

\section{Discussion}

Our results demonstrate several novel-finding on caspase 3-involved neurodegeneration, synaptic plasticity, reactive gliosis, and neurogenesis in KA-mediated excitotoxicity. KA induced an acute neurodegeneration in hippocampus detected by FJB-staining which occurred in CA1/ 3-pyramidal neurons and DG-hilar neurons (Figure 1a, b). The similar FJB-labeled neurodegeneration was also observed in the previous study [37]. Another type of delayed and irreversible neurodegeneration in CA3 and DG-hilus was also detected by the loss of NeuN expression (Figure 1a, c). KA induces different neurodegeneration among CA1, CA3 and DG-hilus regions which may be due to that the stratum lucidum region of CA3 is highly enriched with high-affinity KA binding sites [38]. CA3 neurons are directly excited by stimulation of their
KA receptors and indirectly, by increased glutamate efflux secondary to KA stimulation of mossy fibers $[39,40]$. Therefore, the transient neurodegeneration detected by the loss of NeuN expression in CA1 may be also derived from the mild insult in CA1. It is puzzling that the neurodegeneration (NeuN-loss) occurs transiently in CA1 area at day 5 post KA injection. It can also be explained by KA-induced a transient loss of NeuN mRNA or protein.

It is unclear whether microglial activation initiates the disease progression or that merely response to neuronal death [39]. In our present study, microglia are activated in two phase after KA-injection (Figure 3). The first phase activation may be derived from KA-mediated excitotoxicity that may subsequently affect neurogenesis [41-43], synaptic stripping [44,45], and gliosis [46,47]. Moreover, reactive glial cells produced pro- and antiinflammatory cytokines, chemokines, neurotrophic factors and other modulators to be involved in neuron-glia communication. Previous studies have indicated that the initial limbic seizures increase hippocampal neurogenesis [14-17]. In our study, KA-mediated an acute neurogenesis include the proliferation of radial glial cells and increase of newly born neurons (Figure 7a, b).

KA-induced non-apoptotic caspsae 3 activation is both cell type and region specific (Figure 2) which is similar 

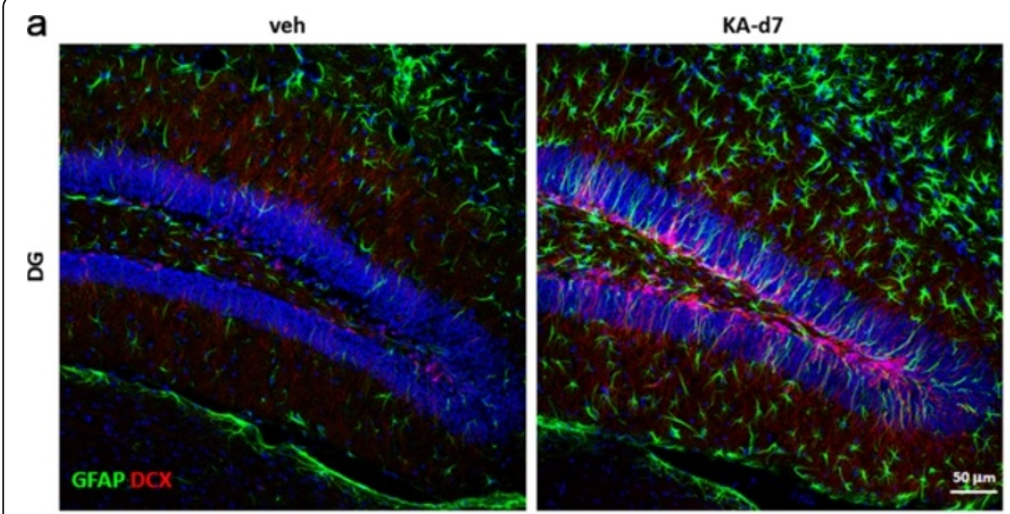

b
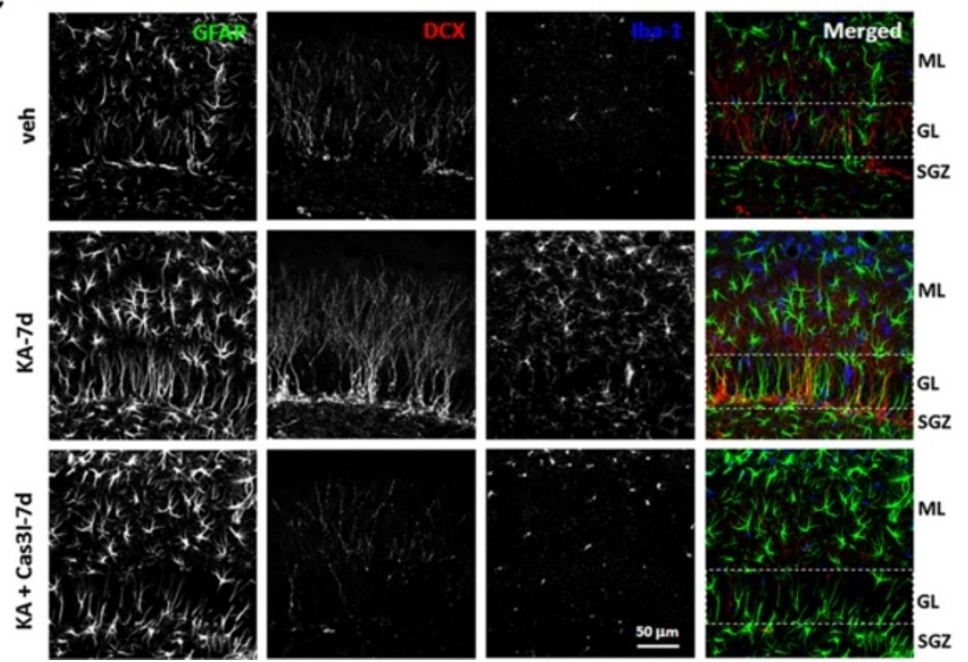

Figure 8 Caspase 3 inhibitor prevents the KA-promoted hippocampal neurogenesis and microglial activation, but not astrogliosis, in the KA-icv-injected mice. CD-1 mice received KA-icv-injections and were sacrificed at day 1 to 7 post KA-injection. For control, the mice were sacrificed at day 7 post vehicle-injection (veh). (a and $\mathbf{b})$ The neurogenesis and astrogliosis in the ipsilateral side of DG was examined by anti-DCX (red) and anti-GFAP (green) antibodies. Cell nuclei were stained with Hoechst 33258 (blue). Panel (a) shows the representative GFAP and DCX fluorescent images of DG at day 7 post KA-injection as compared with vehicle injection. Panel (b) shows the calculated number of DCX-positive neurons in $250 \mu \mathrm{m} \times 250 \mu \mathrm{m}$ field. The data are represented as the percentage related to the control (veh). (c and d) CD-1 mice received KA-icv-injections alone (KA-7d) or co-injection of KA with caspase 3 inhibitor (KA + Cas3l-7d) or vehicle (veh), and were sacrificed at day 7 post KA-injection. The neurogenesis, microglial activation and astrogliosis in the suprapyramidal blade of DG was examined by anti-DCX (red), anti-GFAP (green) and anti-lba-1 (blue) antibodies, respectively. Panel (c) shows the representative fluorescent images of GFAP, DCX and Iba-1 of DG at day 7 post KA-injection as compared with vehicle injection. The dotted lines define the molecular layer (ML), granular layer (GL) and subgranular zone (SGZ) of DG. Panel (d) shows the calculated number of DCX-positive neurons in the $250 \mu \mathrm{m} \times 250 \mu \mathrm{m}$ field. The results are the mean \pm S.D. from 8 images. Significant differences between the control (veh) and the KA injection are indicated by $* *$, $P<0.001$. Significant differences between the KA injection alone and the co-injection of KA and caspase 3 inhibitor are indicated by \#\#, $P<0.001$.

to the previous report [48]. KA-induced caspsae 3 activation in CA1 is located in the cell body of pyramidal neurons. In CA3, however, it is located in both cell body of pyramidal neurons and the neurites in stratum radiatum. Alternatively, caspase 3 activation is located in interneurons in DG-hilus. The different onset of caspase 3 activation in CA1, CA3 and DG-hilus may due to that CA3 is highly accessible to KA-mediated excitotoxicity [38]. A similar nuclear activation of caspase 3 in neurons has been described previously [49,50]. Those studies suggested that SE-mediated nuclear caspase 3 activation may activate caspase-activated DNase (CAD) results in DNA fragmentation and apoptosis [51]. However, caspase 3 activity may be suppressed by inhibitors of apoptotic proteins (IAP), which promotes neuronal survival [52,53]. Previous study indicated that apoptotic caspase 3 activation following SE [32,33,48]. However, they found that caspase 3 contributes to the cell death in only a small proportion of degenerating cells. Henshall et. al. [32] claimed that caspase 3 may play a significant role in the mechanism by which neurons die following seizures. They also found that caspase-3 inhibitor significantly 
improved neuronal survival following seizures. However, in their IHC data, the TUNEL-neurons were colocalized with the IR of caspase 3, but not the activated caspase 3 . Therefore, the increased caspase3-IR may not reflect the activated caspase 3 in the apoptotic neurons.

The non-apoptotic caspase 3 activation may also involve in astrocyte differentiation [54,55]. Cleaved GFAP has been previously detected during neurotoxic process, and GFAP fragments have also been identified as the head domain cleaved GFAP by calpain or caspase 3 [27,29]. We assessed hippocampal GFAP levels by immunoblotting (Figure 6a). GFAP-IR was significantly increased after KAinjection. Full length GFAP (52 kDa) was progressively cleaved into smaller fragments of $45 \mathrm{kDa}$ and $40 \mathrm{kDa}$ by calpain and caspase 3, respectively. The KA-mediated production of $40 \mathrm{kDa}$ fragment was inhibited by the coinjection of caspase 3 inhibitor (Figure 6b) confirm the involvement of caspase 3 .

The express of active caspase 3 in the GFAP-positive radial glial cells increased after KA-injection suggests that caspase 3 functions as a regulatory molecule in neurogenesis [56,57]. The co-injection of caspase 3 inhibitor prevent KA-mediated increase of radial glial cells, newly born neurons, and activated microglia, but not the astrogliosis, suggesting that astroglial caspase 3 was activated after gross astrogliosis, which then regulate microglial activation and neurogenesis. Microglia has been described to be a mediator of neurogenesis [42]. Thus the first phase microglial activation may involve the KA-mediated neurogenesis, and which was inhibited by caspase 3 inhibitor. Further investigation is needed to determine key components of this potential mechanism of astrogliosis, including the subcellular localization of active caspases, the identity of relevant transcription factors, and the relationships between these components and regulation of specific factors such as glutamine synthetase and fibroblast growth factor-2 [57]. In the reactive neonatal astrocyte cultures, specific inhibition of caspases 3 attenuated glutamine synthetase and fibroblast growth factor- 2 expression, but did not reverse the morphological reactive phenotype may explain why caspase 3 inhibitor did not alter astrogliosis in our study.

Caspase 3 has been implicated in synaptic remodeling $[24,28,58]$, cell differentiation [26,59], and cytoskeletal remodeling $[25,60,61]$. We detected the non-apoptotic caspase 3 activities in post synaptic density, which triggered the dominant removal of the GluR1 and SAP-120, but not GluR2 and NR1 from postsynaptic sites. These molecular modifications may correlate with spine degeneration [62]. Proteolytic cleavage of CN-A was significantly reduced when caspase 3 was inhibited, confirming the direct involvement of caspase 3 activation in the dendritic plasticity alteration and astrogliosis after KAinjection. These molecular modifications may correlate with spine degeneration which was observed via the GluR1 removal from PSD and the proteolytic activation of $\mathrm{CN}-\mathrm{A}$ in hippocampus [63]. Our study is the first time to reveal a caspase 3-dependent mechanism that contributes to synaptic molecular change in KA-mediated neurotoxicity. A similar synaptic modification was described in a mouse model of Alzheimer's disease [64].

The KA-mediated neuroplasticity alteration was detected by examining the loss of the PSD-proteins, especially the GluR1, in the PSD domain. Therefore, the activation of caspase 3 may be important for the integrity of neurites which is required for the neuroplasticity. However, the neuritic structures were disturbed seriously by the injection of KA combined with caspase 3 inhibitor but not by KA alone (Figure 5). Therefore, neuroplasticity alteration was detected by the proteolytic activation of $\mathrm{CN}$ A. The result indicated that the proteolytic activation of $\mathrm{CN}-\mathrm{A}$ was inhibited by the co-injected caspase 3 inhibitor (Figure 6b, c).

\section{Conclusions}

Our results provide the first direct evidence of a causal role of caspase 3 activation in the cellular changes during KA-mediated excitotoxicity. These findings may highlight novel pharmacological strategies to arrest disease progression and control seizures that are refractory to classical anticonvulsant treatment.

\section{Competing interests}

The authors declare that they have no competing interests.

\section{Authors' contributions}

TIT and HJT participated in the design of the study and performed the statistical analysis. LC, CLH and THL carried out the animal experiment and immunoassays. FLH participated in figure editing. YJS participated in its design and coordination and helped to draft the manuscript. All authors read and approved the final manuscript.

\section{Acknowledgements}

This study was supported by Grant NSC-97-2320-B-077-003-MY3 from the National Science Council, Grant NRICM-98-DBCM-06 from the National Research Institute of Chinese Medicine, Brain Research Center, National Yang-Ming University, and Grants 99A-C-B6 and100A-C-B5 from the Ministry of Education, Aim for the Top University Plan, Taiwan, R. O. C.

\section{Author details}

'Institute of Biopharmaceutical Science, National Yang-Ming University, Taipei 112, Taiwan. ${ }^{2}$ Institute of Neuroscience, Brain Research Center, school of life science, National Yang-Ming University, Taipei 112, Taiwan. ${ }^{3}$ Division of Basic Chinease Medicine, National Research Institute of Chinese Medicine, Taipei 112, Taiwan. ${ }^{4}$ Institute of Anatomy and Cell Biology, National Yang-Ming University, Taipei 112, Taiwan. ${ }^{5} \mathrm{Ph}$. D Program for the Clinical Drug Discovery from Botanical Herbs, College of Pharmacy, Taipei Medical University, Taipei 110, Taiwan. ${ }^{6}$ National Research Institute of Chinese Medicine, NO. 155-1. Sec. 2, LiNung St., Peitou, Taipei, Taiwan.

Received: 13 August 2013 Accepted: 2 December 2013

Published: 6 December 2013

\section{References}

1. Pitkanen A, Sutula TP: Is epilepsy a progressive disorder? Prospects for new therapeutic approaches in temporal-lobe epilepsy. Lancet Neurol 2002, 1:173-181 
2. McNamara JO, Huang $Y Z$, Leonard AS: Molecular signaling mechanisms underlying epileptogenesis. Sci STKE 2006, 2006:re12.

3. Pitkanen A, Kharatishvili I, Karhunen H, Lukasiuk K, Immonen R, Nairismagi J, Grohn O, Nissinen J: Epileptogenesis in experimental models. Epilepsia 2007, 48(Suppl 2):13-20.

4. Rakhade SN, Jensen FE: Epileptogenesis in the immature brain: emerging mechanisms. Nat Rev Neurol 2009, 5:380-391.

5. Aroniadou-Anderjaska V, Fritsch B, Qashu F, Braga MF: Pathology and pathophysiology of the amygdala in epileptogenesis and epilepsy. Epilepsy Res 2008, 78:102-116.

6. Armijo JA, Valdizán EM, De Las Cuevas I, Cuadrado A: Advances in the physiopathology of epileptogenesis: molecular aspects. Rev Neurol 2002, 34:409-429.

7. Bertram E: The relevance of kindling for human epilepsy. Epilepsia 2007, 48(Suppl 2):65-74

8. Oprica M, Spulber SD, Aronsson AF, Post C, Winblad B, Schultzberg M: The influence of kainic acid on core temperature and cytokine levels in the brain. Cytokine 2006, 35:77-87.

9. Benkovic SA, O'Callaghan JP, Miller DB: Regional neuropathology following kanic acid intoxication in adult and aged C57BL/6J mice. Brain Res 2006, 1070:215-231.

10. Sharma AK, Reams RY, Jordan WH, Miller MA, Thacker HL, Snyder PW: Mesial temporal lobe epilepsy: pathogenesis, induced rodent models and lesions. Toxicol Pathol 2007, 35:984-999

11. Hellier JL, Patrylo PR, Buckmaster PS, Dudek FE: Recurrent spontaneous motor seizures after repeated low-dose systemic treatment with kainate: assessment of a rat model of temporal lobe epilepsy. Epilepsy Res 1998, 31:73-84.

12. Okazaki MM, Molnár $P$, Nadler JV: Recurrent mossy fiber pathway in rat dentate gyrus: synaptic currents evoked in presence and absence of seizure-induced growth. J Neurophysio/ 1999, 81:1645-1660.

13. Sendrowski K, Sobaniec W: Hippocampus, hippocampal sclerosis and epilepsy. Pharmacol Rep 2013, 65:555-565.

14. Parent JM: Injury-induced neurogenesis in the adult mammalian brain. Neuroscientist 2003, 9:261-272.

15. Scharfman HE, McCloskey DP: Postnatal neurogenesis as a therapeutic target in temporal lobe epilepsy. Epilepsy Res 2009, 85:150-161.

16. Shapiro LA, Ribak CE, Jessberger S: Structural changes for adult-born dentate granule cells after status epilepticus. Epilepsia 2008, 5(Suppl 5):13-18.

17. Zhao CS, Overstreet-Wadiche L: Integration of adult generated neurons during epileptogenesis. Epilepsia 2008, 49(Suppl 5):3-12.

18. Scharfman HE, Hen R: Neuroscience. Is more neurogenesis always better? Science 2007, 315:336-338

19. Kuruba R, Hattiangady B, Shetty AK: Hippocampal neurogenesis and neural stem cells in temporal lobe epilepsy. Epilepsy Behav 2009, 14(Suppl 1):65-73.

20. Seifert G, Carmignoto G, Steinhäuser C: Astrocyte dysfunction in epilepsy. Brain Res Rev 2009, 63:212-221.

21. Borges $K$, McDermott $D$, Irier $H$, Smith $Y$, Dingledine R: Degeneration and proliferation of astrocytes in the mouse dentate gyrus after pilocarpineinduced status epilepticus. Exp Neurol 2006, 201:416-427.

22. Ding S, Fellin T, Zhu Y, Lee SY, Auberson YP, Meaney DF, Coulter DA Carmignoto G, Haydon PG: Enhanced astrocytic $\mathrm{Ca}^{2+}$ signals contribute to neuronal excitotoxicity after status epilepticus. J Neurosci 2007, 27:10674-10684

23. Oberheim NA, Tian GF, Han X, Peng W, Takano T, Ransom B, Nedergaard M: Loss of astrocytic domain organization in the epileptic brain. J Neurosci 2008, 28:3264-3276

24. Gilman CP, Mattson MP: Do apoptotic mechanisms regulate synaptic plasticity and growth-cone motility? Neuromol Med 2002, 2:197-214.

25. Acarin L, Villapol S, Faiz M, Rohn T, Castellano B, González B: Caspase-3 activation in astrocytes following postnatal excitotoxic damage correlates with cytoskeletal remodeling but not with cell death or proliferation. Glia 2007, 55:954-965

26. Oomman S, Strahlendorf H, Dertien J, Strahlendorf J: Bergmann glia utilize active caspase-3 for differentiation. Brain Res 2006, 1078:19-34.

27. Fujita K, Yamauchi M, Matsui T, Titani K, Takahashi H, Kato T, Isomura G, Ando $M$, Nagata $Y$ : Increase of glial fibrillary acidic protein fragments in the spinal cord of motor neuron degeneration mutant mouse. Brain Res 1998, 785:31-40

28. D'Amelio M, Cavallucci V, Cecconi F: Neuronal caspase-3 signaling: not only cell death. Cell Death Differ 2010, 17:1104-1114.
29. Mouser PE, Head E, Ha KH, Rohn TT: Caspase-mediated cleavage of glial fibrillary acidic protein within degenerating astrocytes of the Alzheimer's disease brain. Am J Pathol 2006, 168:936-946.

30. MCLin JP, Steward O: Comparison of seizure phenotype and neurodegeneration induced by systemic kainic acid in inbred, outbred, and hybrid mouse strains. Eur J Neurosci 2006, 24:2191-202.

31. Racine RJ: Modification of seizure activity by electrical stimulation. II. Motor seizure. Electroencephalogr Clin Neurophysiol 1972, 32:281-294.

32. Henshall DC, Chen J, Simon RP: Involvement of caspase-3-like protease in the mechanism of cell death following focally evoked limbic seizures. J Neurochem 2000, 74:1215-1223.

33. Narkilahti S, Nissinen J, Pitkänen A: Administration of caspase 3 inhibitor during and after status epilepticus in rat: effect on neuronal damage and epileptogenesis. Neuropharmacology 2003, 44:1068-1088.

34. Schmued LC, Hopkins KJ: Fluoro-Jade B: a high affinity fluorescent marker for the localization of neuronal degeneration. Brain Res 2000, 874:123-130.

35. Hopkins KJ, Wang GJ, Schmued LC: Temporal progression of kainic acid induced neuronal and myelin degeneration in the rat forebrain. Brain Res 2000, 864:69-80

36. Binder LI, Frankfurter A, Rebhun LI: Differential localization of MAP-2 and tau in mammalian neurons in situ. Ann N Y Acad Sci 1986, 466:145-166.

37. Poirier JL, Capek R, De Koninck Y: Differential progression of Dark Neuron and Fluoro-Jade labeling in the rat hippocampus following pilocarpine-induced status epilepticus. Neuroscience 2000, 97:59-68.

38. Ben-Ari Y, Cossart R: Kainate, a double agent that generates seizures: two decades of progress. Trends Neurosci 2000, 23:580-587.

39. Zhang XM, Zhu J: Kainic acid-induced neurotoxicity: targeting glial responses and glia-derived cytokines. Curr Neuropharmacol 2011, 9:388-398.

40. Vincent $P$, Mulle $C$ : Kainate receptors in epilepsy and excitotoxicity. Neuroscience 2009, 158:309-323.

41. Ekdahl CT, Kokaia Z, Lindvall O: Brain inflammation and adult neurogenesis: the dual role of microglia. Neuroscience 2009, 158:1021-1029.

42. Kohman RA, Rhodes JS: Neurogenesis, inflammation and behavior. Brain Behav Immun 2013, 27:22-32.

43. Belarbi K, Rosi S: Modulation of adult-born neurons in the inflamed hippocampus. Front Cell Neurosci 2013, 7:145.

44. Kettenmann H, Kirchhoff F, Verkhratsky A: Microglia: new roles for the synaptic stripper. Neuron 2013, 77:10-18.

45. Wake H, Moorhouse AJ, Miyamoto A, Nabekura J: Microglia: actively surveying and shaping neuronal circuit structure and function. Trends Neurosci 2013, 36:209-217.

46. Zhang D, Hu X, Qian L, O'Callaghan JP, Hong JS: Astrogliosis in CNS pathologies: is there a role for microglia? Mol Neurobiol 2010, 41:232-241.

47. Chen Z, Duan RS, Quezada HC, Mix E, Nennesmo I, Adem A, Winblad B, Zhu J: Increased microglial activation and astrogliosis after intranasal administration of kainic acid in C57BL/6 mice. J Neurobiol 2005, 62:207-218.

48. Narkilahti S, Pirttilä TJ, Lukasiuk K, Tuunanen J, Pitkänen A: Expression and activation of caspase 3 following status epilepticus in the rat. Eur $J$ Neurosci 2003, 18:1486-1496.

49. Schindler CK, Pearson EG, Bonner HP, So NK, Simon RP, Prehn JH, Henshall DC: Caspase-3 cleavage and nuclear localization of caspase-activated DNase in human temporal lobe epilepsy. J Cereb Blood Flow Metab 2006, 26:583-589.

50. Chuang YC, Chen SD, Liou CW, Lin TK, Chang WN, Chan SH, Chang AY: Contribution of nitric oxide, superoxide anion, and peroxynitrite to activation of mitochondrial apoptotic signaling in hippocampal CA3 subfield following experimental temporal lobe status epilepticus. Epilepsia 2009, 50:731-746.

51. Nagata S, Nagase H, Kawane K, Mukae N, Fukuyama H: Degradation of chromosomal DNA during apoptosis. Cell Death Diff 2003, 10:108-116.

52. Vaughan AT, Betti CJ, Villalobos MJ: Surviving apoptosis. Apoptosis 2002, 7:173-177.

53. McLaughlin B: The kinder side of killer proteases: caspase activation contributes to neuroprotection and CNS remodeling. Apoptosis 2007, 9:111-121.

54. Kuranaga E, Miura M: Nonapoptotic functions of caspases: caspases as regulatory molecules for immunity and cell-fate determination. Trends Cell Biol 2007, 17:135-144. 
55. Wagner DC, Riegelsberger UM, Michalk S, Härtig W, Kranz A, Boltze J: Cleaved caspase-3 expression after experimental stroke exhibits different phenotypes and is predominantly non-apoptotic. Brain Res 2011, 1381:237-242.

56. Fernando $P$, Brunette $S$, Megeney LA: Neural stem cell differentiation is dependent upon endogenous caspase 3 activity. FASEB J 2005, 19:1671-1673.

57. Aras R, Barron AM, Pike CJ: Caspase activation contributes to astrogliosis. Brain Res 2012, 1450:102-115

58. Campbell DS, Holt CE: Apoptotic pathway and MAPKs differentially regulate chemotropic responses of retinal growth cones. Neuron 2003, 37:939-952.

59. Finckbone V, Oomman SK, Strahlendorf HK, Strahlendorf JC: Regional differences in the temporal expression of non-apoptotic caspase-3-positive bergmann glial cells in the developing rat cerebellum. Front Neuroanat 2009, 3:3.

60. Villapol S, Acarin L, Faiz M, Castellano B, Gonzalez B: Distinct spatial and temporal activation of caspase pathways in neurons and glial cells after excitotoxic damage to the immature rat brain. J Neurosci Res 2007, 85:3545-3556.

61. Villapol S, Acarin L, Faiz M, Castellano B, Gonzalez B: Survivin and heat shock protein $25 / 27$ colocalize with cleaved caspase-3 in surviving reactive astrocytes following excitotoxicity to the immature brain. Neuroscience 2008, 153:108-119.

62. Fitzjohn SM, Doherty AJ, Collingridge GL: Promiscuous interactions between AMPA-Rs and MAGUKs. Neuron 2006, 52:222-224.

63. Halpain S, Hipolito A, Saffer L: Regulation of F-actin stability in dendritic spines by glutamate receptors and calcineurin. J Neurosci 1998, 18:9835-9844

64. D'Amelio M, Cavallucci V, Middei S, Marchetti C, Pacioni S, Ferri A, Diamantini A, De Zio D, Carrara P, Battistini L, Moreno S, Bacci A Ammassari-Teule M, Marie H, Cecconi F: Caspase-3 triggers early synaptic dysfunction in a mouse model of Alzheimer's disease. Nat Neurosci 2011 14:69-76.

doi:10.1186/1423-0127-20-90

Cite this article as: Tzeng et al:: Caspase 3 involves in neuroplasticity, microglial activation and neurogenesis in the mice hippocampus after intracerebral injection of kainic acid. Journal of Biomedical Science 2013 20:90.

\section{Submit your next manuscript to BioMed Central and take full advantage of:}

- Convenient online submission

- Thorough peer review

- No space constraints or color figure charges

- Immediate publication on acceptance

- Inclusion in PubMed, CAS, Scopus and Google Scholar

- Research which is freely available for redistribution 